\title{
COMUNICAÇÃO
}

\section{PRODUÇÃO DO TARO 'CHINÊS', EM CULTIVO SOLTEIRO E CONSORCIADO COM CHICÓRIA}

\author{
Yield of 'Chinês' taro in monocrop system and intercropped with chicory
}

\author{
Néstor Antonio Heredia Zárate ${ }^{1}$, Maria do Carmo Vieira², João Dimas Graciano ${ }^{3}$, Marcelo Helmich ${ }^{4}$, \\ Rosimeire Pereira Gassi ${ }^{5}$, Cleila Marcondes de Souza ${ }^{6}$
}

\begin{abstract}
RESUMO
Objetiva-se com este trabalho avaliar a produtividade e a renda bruta do taro 'Chinês', conduzido em cultivo solteiro ou consorciado com chicória 'Escarola Lisa', nas condições ambientes de Dourados-MS. Os tratamentos foram arranjados no delineamento experimental de blocos casualizados, com cinco repetições. A colheita da chicória foi aos 97 dias após a semeadura e a do taro aos 203 dias. O consórcio foi avaliado pela razão de área equivalente (RAE) e sua validação pela renda bruta. As plantas de taro e de chicória foram influenciadas significativamente pela consorciação, exceto para altura das plantas de chicória que foram semelhantes. O cultivo solteiro proporcionou maiores produções de taro $\left(9,90 ; 3,96 ; 10,42\right.$ e $9,03 \mathrm{t} \mathrm{ha}^{-1}$ de folhas, rizomas-mãe, rizomas-filho comerciais e rizomas-filho não comerciais, respectivamente) e diâmetro $(19,22 \mathrm{~cm})$ e número $\left(50,69\right.$ mil ha $\left.^{-1}\right)$ de cabeças comerciais de chicória. A RAE para o consórcio taro-chicória foi de 0,92 e, por isso, o consórcio foi considerado como não efetivo.
\end{abstract}

Termos para indexação: Colocasia esculenta, Cichorium endivia, associação de culturas, renda.

\begin{abstract}
The present work had the aim of evaluating the yield and gross income of 'Chinês' taro that was carried out in monocrop and intercropped system with 'Escarola Lisa' chicory in environment conditions in Dourados-MS. Treatments were arranged in a randomized experimental block design with five replications. Chicory harvest was done at 97 days after sowing and taro harvest at 203 days. Intercropping was evaluated by Land Equivalent Ratio (LER) and its validation was done determining gross income. Plants of taro and chicory were significantly influenced by means of cultivation, except to height of chicory plants that were similar. Monocrop system induced the highest yields of taro $\left(9.90 ; 3.96 ; 10.42\right.$ and $9.03 \mathrm{t} \mathrm{ha}^{-1}$ of leaves, corms, commercial and noncommercial cormels, respectively) and greatest diameter $(19.22 \mathrm{~cm})$ and number $\left(50.69\right.$ thousand $\left.\mathrm{ha}^{-1}\right)$ of commercial heads of chicory. LER for taro/chicory intercrop was 0.92 and, because of that, it was considered as non-effective.
\end{abstract}

Index terms: Colocasia esculenta, Cichorium endivia, intercrop, income.

(Recebido em 23 de outubro de 2006 e aprovado em 17 de abril de 2007)

Diversos autores abordam a importância dos sistemas de cultivos múltiplos como peça fundamental na manutenção de pequenas propriedades agrícolas, tanto em países subdesenvolvidos quanto como componente de sistemas agrícolas mais sustentáveis (SANTOS, 1998). Muitos produtores associam a técnica do consórcio com redução dos riscos, pois se uma das culturas tem sua produção reduzida a outra pode compensar, em parte, os prejuízos permitindo ao produtor uma colheita razoável (INNIS, 1997).
A escolha criteriosa das culturas componentes, e da época de suas respectivas instalações, é de fundamental importância para que se possa propiciar exploração máxima das vantagens do sistema de cultivo consorciado. Plantas de diferentes alturas, quando em plantio consorciado, poderão utilizar com maior eficiência a energia solar (HARDER et al., 2005; PUIATTI et al., 2000). Todavia, na literatura consultada, não foram encontrados relatos sobre o consórcio de taro (Colocasia esculenta (L.) Schott) com Cichorium endivia L. (chicória).

\footnotetext{
Engenheiro Agrônomo, Doutor, Professores Associado I - Faculdade de Ciências Agrárias/FCA - Universidade Federal da Grande Dourados/UFGD Rodovia Dourados/ltahum, Km12 - Cx. P. 533 - 79804-970 - Dourados, MS - nahz@terra.com.br - Bolsista de Produtividade em Pesquisa do CNPq ${ }^{2}$ Engenheira Agrônoma, Doutora, Professora Titular da Faculdade de Ciências Agrárias/FCA - Universidade Federal da Grande Dourados/UFGD Rodovia Dourados/Itahum, Km12 - Cx. P. 533 - 79804-970 - Dourados, MS - vieiracm@terra.com.br - Bolsista de Produtividade em Pesquisa do CNPq ${ }^{3}$ Bacharel em Zootecnia, Doutor, Professor Associado I da Faculdade de Ciências Agrárias/FCA - Universidade Federal da Grande Dourados/UFGD Cx. P. 533 - 79804-970 - Dourados, MS - jdimas@ufgd.edu.br

${ }^{4}$ Graduanda em Agronomia - Faculdade de Ciências Agrárias/FCA - Universidade Federal da Grande Dourados/UFGD - Rodovia Dourados/Itahum, Km12 - Cx. P. 533 - 79804-970 - Dourados, MS - m.helmich@terra.com.br

${ }^{5}$ Engenheira Agrônoma, Doutoranda em Agronomia - Faculdade de Ciências Agrárias/FCA - Universidade Federal da Grande Dourados/UFGD Rodovia Dourados/Itahum, Km12 - Cx. P. 533 - 79804-970 - Dourados, MS - rpgassi@yahoo.com.br - Bolsista do CNPq

${ }^{6}$ Graduanda em Ciências Biológicas - Faculdade de Ciências Biológicas e Ambientais/FCBA - Universidade Federal da Grande Dourados/UFGD Rodovia Dourados/Itahum, Km12 - Cx. P. 533 - 79804-970 - Dourados, MS - cleilamar8@yahoo.com.br
} 
O taro é uma Araceae utilizada na agricultura e dieta alimentar de muitos países tropicais, por ser um alimento rico em amido, por ter grande produção por unidade de área, ser pouco exigente em gastos com mãode-obra e insumos e, por ser de fácil conservação; tem ainda, habilidade para se desenvolver em locais alagados (com água em movimentação, como nas beiras dos rios) ou secos (sob irrigação) o que faz dessa espécie uma cultura de subsistência ideal para áreas onde ainda não se usam tecnologias avançadas (HEREDIA ZÁRATE \& VIEIRA, 2004a). Por suas características nutricionais, o taro, apresenta possibilidades de uso humano sob diferentes formas de preparo, podendo substituir, total ou parcialmente, a batatinha, a mandioca, o milho, o trigo e outras espécies amídicas. Também, pode ser utilizado na alimentação animal, especialmente para frangos de corte (HEREDIA ZÁRATE et al., 2005).

A chicória é uma hortaliça folhosa, semelhante à alface, entretanto, suas folhas não formam cabeça, sendo crespas ou lisas, conforme a variedade. É uma espécie que produz melhor sob temperaturas amenas, embora havendo cultivares tolerantes a temperaturas elevadas. Geralmente semeia-se no outuno-inverno, porém pode-se cultivar ao longo do ano, em regiões de altitude. A propagação se efetua por sementes, com ou sem transplante, no espaçamento de $0,30 \mathrm{~m}$ entre linhas e $0,30 \mathrm{~m}$ entre plantas ou 0,40 m x 0,30 m. A colheita é feita aos 65-80 dias após a semeadura, cortando-se a planta inteira (parte aérea). $\mathrm{O}$ valor comercial da chicória costuma ser menor que o da alface, porém, o preço é mais estável, ao longo do ano (FILGUEIRA, 2000).

Face à importância de se avaliar o desempenho dos cultivos consorciados regionalmente, objetivou-se com este trabalho avaliar a produtividade do taro 'Chinês', conduzido em cultivo solteiro ou consorciado com chicória, nas condições ambientes de Dourados-MS.

O trabalho foi desenvolvido na Universidade Federal de Mato Grosso do Sul, em Dourados-MS, em solo LATOSSOLO VERMELHO distroférrico, de textura argilosa, com as seguintes características químicas: 5,5 de pH em $\mathrm{CaCl}_{2} ; 34,0 \mathrm{~g} \mathrm{dm}^{-3}$ de M.O; 36,0 mg dm${ }^{-3}$ de P; 6,6; 56,0 e 22,6 $\mathrm{mmol}_{\mathrm{c}} \mathrm{dm}^{-3}$ de $\mathrm{K}, \mathrm{Ca}$ e $\mathrm{Mg}$, respectivamente. O município de Dourados situa-se em latitude de $22^{\circ} 13^{\prime} 16^{\prime \prime S}$, longitude de $54^{\circ} 17^{\prime} 01^{\prime \prime W}$ e altitude de $430 \mathrm{~m}$. O clima da região, segundo a classificação de Köppen, é Mesotérmico Úmido; do tipo Cwa. As temperaturas máximas e mínimas e a precipitação na época de desenvolvimento do experimento são apresentadas na Figura 1.

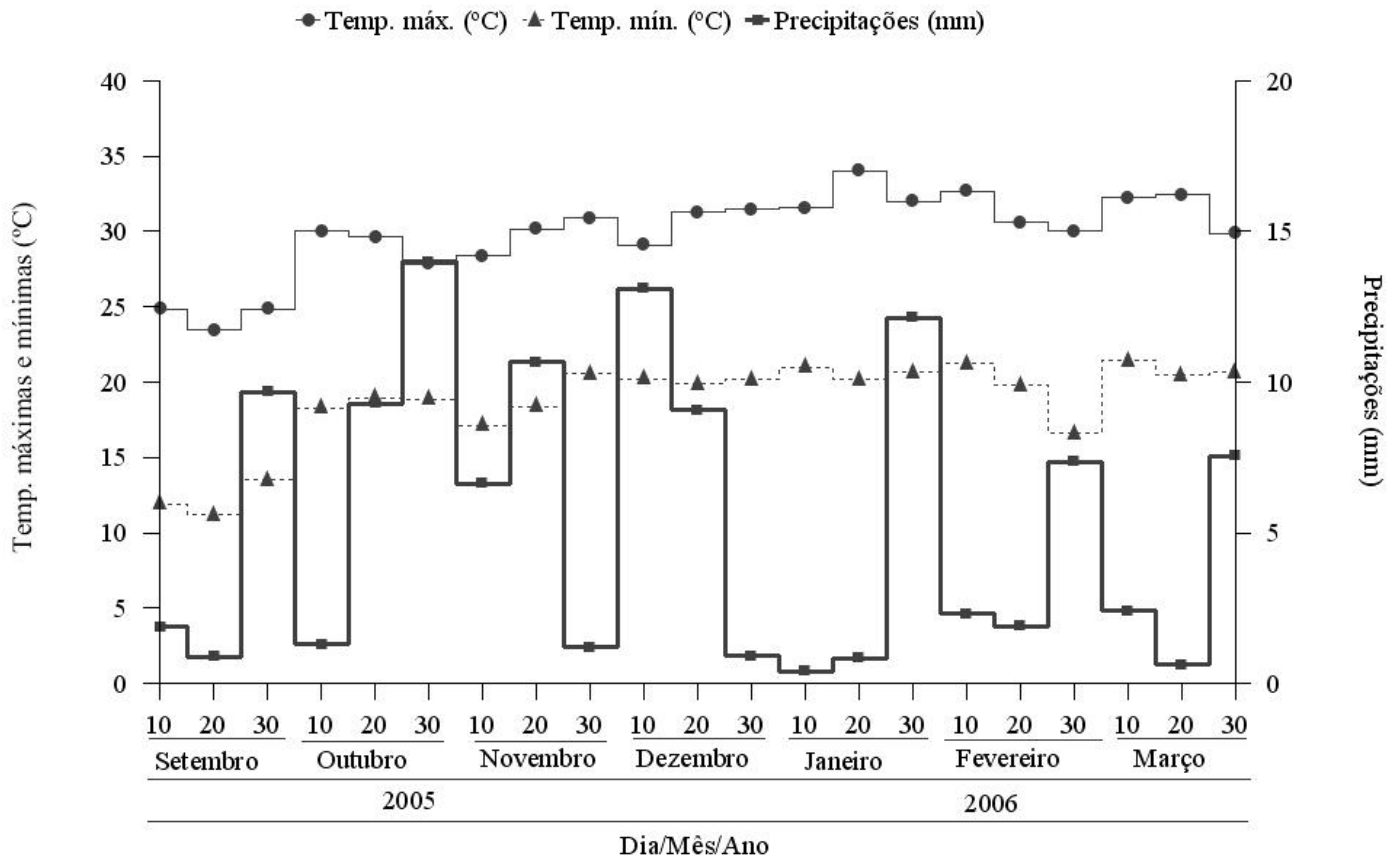

FIGURA 1 - Temperaturas máximas e mínimas e precipitação na época de desenvolvimento do experimento. Dourados, UFGD, 2005-2006. 
Foi estudado o taro 'Chinês', em cultivo solteiro e consorciado com chicória 'Escarola Lisa', arranjados no delineamento experimental de blocos casualizados, com cinco repetições. As parcelas tiveram área total de $3,0 \mathrm{~m}^{2}$ (1,5 m de largura x 2,0 m de comprimento) e área útil de 2,0 $\mathrm{m}^{2}$ (1,0 $\mathrm{m}$ de largura $\mathrm{x} 2,0 \mathrm{~m}$ de comprimento). Tanto no cultivo solteiro como no consorciado(Figura 2), as parcelas de chicória e de taro foram formadas por um canteiro contendo, respectivamente, quatro (25 cm entre linhas) e duas linhas (50 cm entre linhas) e 10 plantas linha ${ }^{-1}(20 \mathrm{~cm}$ entre plantas) correspondendo às populações de 132.000 plantas ha-1 para a chicória e 66.000 plantas ha-1 $^{-1}$ para o taro.

Para o plantio do taro, foram abertos sulcos de $0,05 \mathrm{~m}$ de largura $\mathrm{x}$ 0,05 $\mathrm{m}$ de profundidade, onde foram colocadas as mudas, no fundo do sulco, em posição horizontal, e cobertas com o solo extraído na abertura dos sulcos. A implantação da chicória foi no sistema de semeadura direta no local definitivo. As irrigações foram feitas por aspersão, mantendo o solo com, aproximadamente, $70 \%$ da capacidade de campo, necessitando de turnos de rega de dois dias. O controle das plantas infestantes foi feito com auxílio de enxadas nas entrelinhas e com arranquio manual dentro das linhas, sempre que necessário.

Na colheita da chicória, feita aos 97 dias após a semeadura, utilizou-se como índice de colheita, a perda de brilho das folhas; nestas foram medidas a altura e o diâmetro das "cabeças" e determinados o número de "cabeças" comerciais e não comerciais. A colheita do taro foi aos 203 dias, quando mais de $50 \%$ da parte aérea das plantas apresentavam-se amareladas e secas, sintomas típicos de senescência, época em que determinaram-se as massas fresca de folhas, rizomas-mãe e rizomas-filho comerciais ( > de $25 \mathrm{~g}$ ) e não comerciais ( $<$ de $25 \mathrm{~g}$ ). Os dados avaliados do taro e da chicória, solteiros e consorciados, foram submetidos à análise de variância e testados pelo teste $\mathrm{F}$, até $5 \%$ de probabilidades.

O consórcio foi avaliado utilizando a expressão da razão de área equivalente (RAE) proposto por Caetano et al. (1999), a saber: $\mathrm{RAE}=\mathrm{Tc} \cdot \mathrm{Ts}^{-1}+\mathrm{Cc} \cdot \mathrm{Cs}^{-1}$, onde, respectivamente, $\mathrm{Tc}$ e $\mathrm{Cc}=$ produções do taro e do número de "cabeças" comerciais de chicória em consorciação e Ts e Cs = produções do taro e do número de "cabeças" comerciais de chicória em cultivo solteiro. A validação do consórcio foi realizada pela determinação da renda bruta. Para o cálculo da renda bruta, foram pesquisados os preços pagos aos produtores pela "cabeça" comercial de chicória (R\$ 0,35 a unidade) e o kilograma de rizomas-filho comerciais do taro ( $\left.\mathrm{R} \$ 1,20 \mathrm{~kg}^{-1}\right)$; posteriormente, efetuaramse as conversões por hectare, por cultivo e total.

As plantas de taro e de chicória foram influenciadas significativamente pela forma de cultivo, exceto para altura das plantas de chicória que foram semelhantes (Tabela 1). O cultivo solteiro proporcionou as maiores produções de taro $\left(9,90 ; 3,96 ; 10,42\right.$ e $9,03 \mathrm{t} \mathrm{ha}^{-1}$ de folhas, rizomas-mãe, rizomas-filho comerciais e rizomas-filho não comerciais, respectivamente) e diâmetro $(19,22 \mathrm{~cm})$ e número (50,69 mil ha $^{-1}$ ) de cabeças comerciais de chicória. Esses resultados indicam que as plantas solteiras tiveram melhor adaptabilidade que as consorciadas, normalmente relacionadas com a manutenção da eficiência na absorção ou no uso da água, dos nutrientes e do $\mathrm{CO}_{2}$ (LARCHER, 2000).

A diminuição produtiva de 7,33 $\mathrm{t} \mathrm{ha}^{-1}$ de rizomasfilho comerciais do taro e o aumento de 18.750 do número de "cabeças" de chicória não comerciais obtidos no sistema consorciado, em relação ao solteiro $\left(10,42 \mathrm{t} \mathrm{ha}^{-1}\right.$ de taro e 84.030 "cabeças" de chicória não comerciais), evidenciam

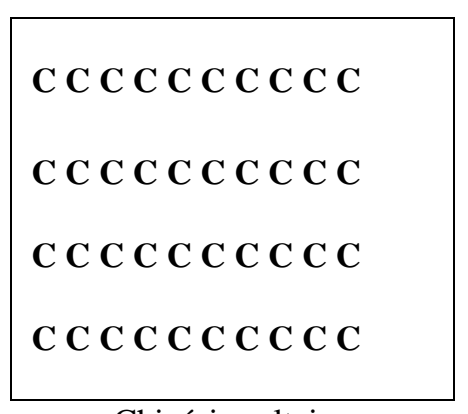

Chicória solteira

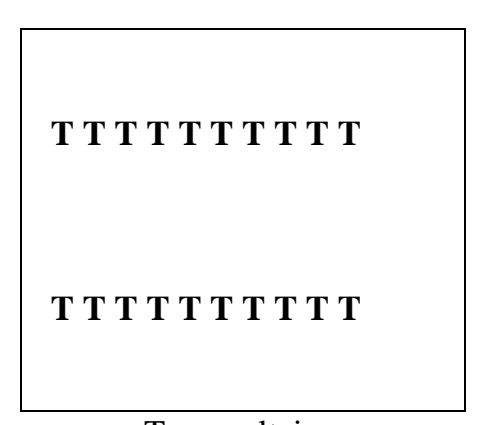

Taro solteiro

\section{C C C C C C C C T T T T T T T T T T C C C C C C C C C \\ C C C C C C C C \\ T T T T T T T T T T C C C C C C C C}

Consórcio chicória com taro

FIGURA 2 - Arranjo de plantas de chicória 'Escarola Lisa' com as de taro 'Chinês, como culturas solteiras e consorciadas. Dourados, UFGD, 2005-2006. 
que houve diferenças na provável capacidade de autoregulação das plantas em relação ao equilíbrio das relações de interferência (LARCHER, 2000). Isso porque as relações fonte-dreno podem ser alteradas pelas condições de cultivo, principalmente em um sistema de culturas múltiplas, geralmente formado por espécies diferentes, onde encontram-se raízes que exploram o solo a diferentes profundidades, ou onde as folhas podem responder diferencialmente à competição por luz (HARDER et al., 2005).

A RAE para o consórcio taro $\mathrm{x}$ chicória foi de 0,92 (Tabela 2) e, neste caso, a consorciação não foi efetiva e não é aconselhável. Isso pode ter relação com a menor competição e melhor aproveitamento do solo quando as plantas estão em sistema solteiro em relação ao consorciado, onde na maioria dos casos, a interação é notada pela redução da produtividade das culturas (SILVA, 1983, citado por HEREDIA ZÁRATE et al., 2005). Por isso, a escolha criteriosa das culturas componentes é de fundamental importância, para que se possa propiciar exploração máxima das vantagens do sistema de cultivo consorciado (HARDER et al., 2005). Isso porque, o objetivo principal da produção agrícola é maximizar lucros, com minimização de custos, então, ao planejar a produção agrícola não se deve pensar somente na produção, mas também na alocação adequada dos recursos disponíveis (HEREDIA ZÁRATE \& VIEIRA, 2004b).

Nas condições em que foi conduzido o experimento e considerando a RAE e a renda bruta, conclui-se que não foi viável o consórcio do taro 'Chinês' com a chicória 'Escarola Lisa'.

TABELA 1 - Produção de folhas, rizomas-mãe e rizomas-filho de taro 'Chinês' e altura, diâmetro e número de cabeças de chicória 'Escarola Lisa', em cultivo solteiro e consorciado. Dourados, UFGD, 2005-2006.

\begin{tabular}{|c|c|c|c|c|c|c|c|c|}
\hline \multirow[t]{3}{*}{ Cultivo } & \multicolumn{4}{|c|}{ Produção de taro $\left(\mathrm{t} \mathrm{ha}^{-1}\right)$} & \multicolumn{4}{|c|}{ Chicória } \\
\hline & \multirow[b]{2}{*}{ Folhas } & \multirow[b]{2}{*}{$\begin{array}{l}\text { Rizoma- } \\
\text { mãe }\end{array}$} & \multicolumn{2}{|c|}{ Rizoma-filho } & \multirow[b]{2}{*}{$\begin{array}{c}\text { Altura } \\
(\mathbf{c m})\end{array}$} & \multirow[b]{2}{*}{$\begin{array}{l}\text { Diâmetro } \\
\text { (cm) }\end{array}$} & \multicolumn{2}{|c|}{ "Cabeças" (Mil ha $\left.{ }^{-1}\right)$} \\
\hline & & & Comercial & $\begin{array}{c}\text { Não } \\
\text { comercial }\end{array}$ & & & Comercial & $\begin{array}{c}\text { Não } \\
\text { comercial }\end{array}$ \\
\hline Solteiro & $9,90 \mathrm{a}$ & $3,96 \mathrm{a}$ & $10,42 \mathrm{a}$ & $9,03 \mathrm{a}$ & $9,43 \mathrm{a}$ & $19,22 \mathrm{a}$ & $50,69 \mathrm{a}$ & $84,03 \mathrm{~b}$ \\
\hline Consórcio & $4,98 \mathrm{~b}$ & $2,50 \mathrm{~b}$ & $3,11 \mathrm{~b}$ & $5,44 \mathrm{~b}$ & $9,72 \mathrm{a}$ & $17,98 \mathrm{~b}$ & $31,25 \mathrm{~b}$ & $102,78 \mathrm{a}$ \\
\hline C.V. $(\%)$ & 42,72 & 15,06 & 55,20 & 7,80 & 4,67 & 3,43 & 20,34 & 3,59 \\
\hline
\end{tabular}

Médias seguidas pelas mesmas letras, nas colunas, não diferem pelo teste $\mathrm{F}$, a $5 \%$ de probabilidade.

TABELA 2 - Razão de área equivalente (RAE) e renda bruta do taro 'Chinês' e da chicória 'Escarola Lisa', em cultivo solteiro e consorciado. Dourados, UFGD, 2005 - 2006.

\begin{tabular}{llcccrc}
\hline Cultivo & Espécie & $\begin{array}{c}\text { Massa Fresca } \\
\left(\mathbf{t ~ h a}^{-\mathbf{1}}\right)\end{array}$ & $\begin{array}{c}\text { "Cabeças" } \\
\left(\mathbf{M i l ~ h a}^{-\mathbf{1}}\right)\end{array}$ & RAE & \multicolumn{2}{c}{$\begin{array}{c}\text { Renda bruta }^{\mathbf{1}} \\
(\mathbf{R} \mathbf{\$})\end{array}$} \\
\hline Solteiro & Taro & 10,42 & & 1,00 & $12.504,00$ & $12.504,00$ \\
& Chicória & & 50,69 & 1,00 & $17.741,50$ & $17.741,50$ \\
\hline Consórcio & Taro & 3,11 & & & $3.732,00$ & \\
& Chicória & & 31,25 & 0,92 & $10.937,50$ & $14.669,50$ \\
\hline
\end{tabular}

${ }^{1} \mathrm{R} \$ 0,35$ a “cabeça” de chicória e $\mathrm{R} \$ 1,20 \mathrm{~kg}^{-1}$ de rizomas-filho comerciais de taro. Fonte: Vendedores de hortaliças no varejo, em 6-3-2006. 


\section{AGRADECIMENTOS}

Ao CNPq, pelas bolsas concedidas e à FUNDECTMS, pelo apoio financeiro.

\section{REFERÊNCIAS BIBLIOGRÁFICAS}

CAETANO, L. C. S.; FERREIRA, J. M.; ARAÚJO, M. de. Produtividade da alface e cenoura em sistema de consorciação. Horticultura Brasileira, Brasília, v. 17, n. 2, p. 143-146, 1999.

FILGUEIRA, F. A. R. Novo manual de olericultura: agrotecnologia moderna na produção e comercialização de hortaliças. Viçosa: UFV, 2000. 402 p.

HARDER, W. C.; HEREDIA ZÁRATE, N. A.; VIEIRA, M. C. Produção e renda bruta de rúcula (Eruca sativa Mill.) 'Cultivada' e de almeirão (Cichorium intybus L.) 'Amarelo', em cultivo solteiro e consorciado. Ciência e Agrotecnologia, Lavras, v. 29, n. 4, p. 775-785, jul./ago. 2005.

HEREDIA ZÁRATE, N. A.; VIEIRA, M. C. Composição nutritiva de rizomas em clones de inhame cultivados em Dourados-MS. Pesquisa Agropecuária Tropical, Goiânia, v. 34, n. 1, p. 61-63, 2004a.
HEREDIA ZÁRATE, N. A.; VIEIRA, M. C. Produção e renda bruta da cebolinha solteira e consorciada com espinafre. Horticultura Brasileira, Brasília, v. 22, n. 4, p. 811-814, out./dez. 2004b.

HEREDIA ZÁRATE, N. A.; VIEIRA, M. C.; OLIVEIRA, A. C. P.; LIMA, A. A. Produção e renda bruta de dois cultivares de taro, em cultivo solteiro e consorciado com alface. Semina: Ciências Agrárias, Londrina, v. 26, n. 3, p. 283 290, jul./set. 2005.

INNIS, D. Q. Intercropping and the scientific basis of the traditional agriculture. London: Intermediate, 1997. 179 p.

LARCHER, W. Ecofisiologia vegetal. São Carlos: RiMa Artes e Textos, 2000. 531 p.

PUIATTI, M.; FÁVERO, C.; FINGER, F. L.; GOMES, J. M. Crescimento e produtividade de inhame e de milho doce em cultivo associado. Horticultura Brasileira, Brasília, v. 18 , n. 1, p. 24-30, mar. 2000.

SANTOS, R. H. S. Interações interespecíficas em consórcio de olerícolas. 1998. 124 f. Tese (Doutorado em Fitotecnia) - Universidade Federal de Viçosa, Viçosa, 1998. 